significantly weaker than that of community controls. Table 1 presents further details.

Conclusions These results indicate that SAM may be associated with a number of adverse long-term effects, including stunting, abnormal body composition and functional impairment. It will be crucial to identify effective strategies, not only to prevent SAM in the first place, but to improve long-term outcomes in SAM survivors. Interventions might include more proactive case finding to encourage earlier detection and continued follow-up after the initial treatment to support high risk children and families.

\begin{tabular}{|c|c|c|c|c|c|}
\hline \multicolumn{2}{|c|}{$\begin{array}{l}\text { Abstract P05 Table } 1 \\
\text { controls }\end{array}$} & \multicolumn{4}{|c|}{ Linear regression of cases vs community } \\
\hline Measurement & $\begin{array}{l}\text { Mean for } \\
\text { Case } \\
\text { (ex-SAM) } \\
\text { children }\end{array}$ & $\begin{array}{c}\text { Mean for } \\
\text { Community } \\
\text { control } \\
\text { children }\end{array}$ & $\begin{array}{c}\text { Cases vs } \\
\text { Community } \\
\text { Regression } \\
\text { Coefficient }\end{array}$ & $\begin{array}{c}95 \% \\
\text { Confid ence } \\
\text { Interv al }\end{array}$ & $\begin{array}{c}\mathrm{p}- \\
\text { value }\end{array}$ \\
\hline Weight-for-age & $-1.6 z$-scores & $-1.2 z$-scores & -0.35 & $-0.61,-0.09$ & 0.01 \\
\hline Height-for-age & -1.8 z-scores & -1.3 z-scores & -0.48 & $-0.77,-0.18$ & $<0.001$ \\
\hline BM-for-age & -0.9 z-scores & -0.7 z-scores & -0.22 & $-0.44,0.00$ & 0.06 \\
\hline $\begin{array}{l}\text { Waist:Hip ratio } \\
(\log )\end{array}$ & 0.91 & 0.88 & 0.03 & $0.01,0.06$ & 0.01 \\
\hline $\begin{array}{l}\text { Sitting } \\
\text { height/standing } \\
\text { height ratio }\end{array}$ & 52.2 & 51.8 & 0.55 & $0.16,0.94$ & 0.01 \\
\hline $\begin{array}{l}\text { Hang grip } \\
\text { strength }(\log )\end{array}$ & $12.2 \mathrm{~kg}$ & $13.8 \mathrm{~kg}$ & -0.12 & $-0.18,-0.05$ & $\varangle 0.001$ \\
\hline $\begin{array}{l}\text { Skinfold } \\
\text { thickness ratio }\end{array}$ & 1.73 & 1.72 & -0.02 & $-0.12,0.07$ & 0.61 \\
\hline
\end{tabular}

\section{P06 DELIVERY OF A SCHOOL HEALTH AND NUTRITION PROGRAMME FOR KENYAN CHILDREN: A FEASIBILITY STUDY}

B Eder, J Bogie, D Magnus. Centre for Child and Adolescent Health, University of Bristol, Bristol, UK

\subsection{6/archdischild-2015-308599.6}

Aims Health is a key factor in enabling universal access to education. Children miss over 200 million days of school every year due to illness. Traditionally, vertical approaches have been used to individually tackle child health and nutrition problems such as malnutrition or malaria. However, these interventions overlook the complex interactions between them. We therefore sought to develop a comprehensive, integrated school health and nutrition programme to produce long-term and sustainable improvements to child health and education outcomes.

Methods A 3 year pilot study was carried out in a population of 2,000 children aged 5-16 in rural Western Kenya. The programme comprised school meals, vitamin A supplementation, insecticide-treated bed nets, deworming, hand washing and health education. Data were collected on programme delivery and on health, nutrition and education parameters.

Results 2103 children were dewormed using Albendazole, supplied with insecticide-treated bed nets and Vitamin A was given to all children under 5 . School meals were provided daily to all children. Additional water points with soap were installed with a $32.5 \%$ observational increase in clean hands and $86 \%$ increased soap use. Preliminary results show increased school enrolment and reductions in school absenteeism (OR 0.70, 95\% CI $0.61-0.82, \mathrm{p}=<0.001$ ), in anaemia (OR $0.25,95 \%$ CI $0.16-0.40, \mathrm{p}=<0.001)$ and undernutrition, both stunting (OR $0.56,95 \%$ CI $0.48-0.65, \mathrm{p}=<0.001$ ) and underweight (OR $0.55,95 \%$ CI $0.42-0.73, \mathrm{p}=0.001$ ).

Conclusion Our experience shows that a comprehensive school health and nutrition programme is feasible and that monitoring for health and education outcomes is possible in this context. The data suggest improvements in childhood anaemia and nutrition in conjunction with improved school attendance and enrolment. Complex interventions for improving school health are feasible and can produce long-term benefits above and beyond vertical programme initiatives.

\section{P07 EVIDENCE-BASED GUIDANCE TO INFORM CONSENT SEEKING IN CHILDREN'S CRITICAL CARE TRIALS}

K Woolfall, L Frith, B Young. Institute of Psychology, Health and Society, University of Liverpool, Liverpool, UK

\subsection{6/archdischild-2015-308599.7}

Aims Challenges in seeking parents' consent for research at the point when their child is critically ill have been a significant barrier to improving treatments for children and conducting trials. In 2008 UK legislation was amended to enable consent for emergency research to be sought after a child has been given the investigational drug or device. This is known as deferred consent. CONNECT is the first UK study to explore parent and practitioner views and experiences of deferred consent in children's clinical care trials. It aimed to integrate evidence and ethical theory to inform practice guidelines to optimise recruitment and consent in this challenging setting.

Methods Mixed methods qualitative and quantitative study with 354 participants (292 parents, 39 nurses, 19 doctors and 4 Clinical Trials Unit practitioners). We integrated findings with previous research and ethical theory to develop draft guidance on deferred consent. The CONNECT advisory group and 32 key stakeholders (critical care practitioners, ethicists and parents) contributed to the development of the final CONNECT guidance.

Results Parents may be initially shocked or angered to discover their child can be entered into a trial without their prior consent. However practitioner explanations of why consent is deferred can help address parents' initial concerns and reassure them. Parents view deferred consent as more acceptable for trials of medical interventions already used in clinical practice than trials involving new interventions or a change in clinical practice. Practitioners experienced in deferred consent describe how families are receptive to the consent method, if conducted sensitively and if the timing is appropriate. CONNECT guidance provides recommendations to inform: 1) pre-trial research for potentially challenging trials; 2) publicising trials that use deferred consent; 3) seeking deferred consent; 4) seeking deferred consent when a child has died; 5) written trial information; and 6) child assent. Conclusion Those involved in the funding, design, conduct and ethical review of critical care trials can use CONNECT guidance to help ensure approaches to deferred consent are appropriate 